\title{
SOBRE AS DIFERENTES FORMAS DE HABITAR AS NORMAS E ATIVAR MODULAÇÕES NO PARENTESCO: UM CASO TICUNA
}

\author{
Patricia Carvalho Rosa (D)
}


RESUMO

Embasado na relação de interlocução e pesquisa realizada com índios Ticuna, população ameríndia habitante de áreas localizadas às margens e aos interflúvios do rio Solimões, no Amazonas, este artigo adota a perspectiva descritiva e narrativa de um "caigüwaecü", "parente com jeito de mulher", para discutir, a partir dela, as formas através das quais um jovem indígena habita as normas que incidem sobre a fabricação generizada da pessoa e produz modulações no parentesco, alterando sua posição de homem solteiro para esposa potencial (namã), recriando para si um domínio de feminino.

Palavras-chave: parentesco; gênero; sexualidade; Ticuna

\section{ON THE DIFFERENT WAYS OF INHABITING NORMS AND ACTIVATING KINSHIP MODULATIONS: A TICUNA CASE}

Based on the interlocution and research relationship conducted with Ticuna interlocutors, an Amerindian population living on the banks and interfluvials of the Solimões River, in the Amazon, this article adopts the descriptive and narrative perspective of a "caiguwaecu", "woman-like relative", to discuss from them the ways in which an indigenous youth inhabits the norms that focus on the generalized fabrication of the person and produces modulations in kinship, changing his position from single man to potential wife (namã), recreating for himself a feminine domain.

Keywords: kinship; gender;
SOBRE LAS DIFERENTES FORMAS DE HABITAR LAS NORMAS Y ACTIVAR VARIACIONES EN EL PARENTESCO: UN CASO TICUNA

\section{RESUMEN}

Basado en la interlocución y la relación de investigación llevada a cabo con interlocutores Ticuna, población amerindia que vive a orillas del río Solimões, en el Amazonas, este artículo adopta la perspectiva descriptiva y narrativa de un "caiguwaecu", "pariente que hace como mujer", para discutir las formas mediante las que un joven indígena habita las normas que inciden sobre la fabricación genérica de la persona y termina por producir variaciones en el parentesco, cambiando su posición de hombre soltero a esposa potencial (namã), recreando para sí mismo un dominio de lo femenino.

Palabras clave: parentesco; género; 


\section{INTRODUÇÃO}

É como ter vontade [de casar] e não poder, sabe? Assim é meu pensamento. Não quero casar com uma prima, aí viro solteiro $[\ldots]$

Para casar terá que ser no meu jeito, eu viro a esposa de alguém. [...] Parentes por aí já dizem que mamãe teve filha, para falar de mim. Estou virando mulher ${ }^{1}$.

Com essas palavras, Nguyaecüe explicava-me sobre algumas ambiguidades e os consequentes dilemas em relação à sua posição pública na aldeia onde mora desde que nasceu, há vinte e poucos anos. Muitos, no pequeno povoado, que conta com aproximadamente 350 pessoas, referem-se a ele como "ngemã", tradução para a condição de solteiro, aquele sem esposa. Ele é tratado também pelos conterrâneos como "caigüwaecü", "parente com jeito de mulher", e cujo estatuto é por ele reafirmado.

“Caigüwaecü” faz alusão ao manejo da sexualidade, ao que a expressão nativa traduz como "homem que usa seu ânus como vagina de mulher" ${ }^{2}$. No caso da interlocução, o termo, quando empregado, carrega jocosidade, cujo valor ético e moral está localmente englobado em um regime de pedagogias cotidianas associadas à produção do corpo e da pessoa indígena, no qual o repertório de experiências para a aquisição das capacidades agentivas do gênero feminino é destoante, "um pouco confuso", comentavam alguns de seus parentes. Ocupar a posição de caigüwaecü o aloca, pois, em uma condição de ambiguidade, justificando, para ele, os motivos da "desconfiança" que o acompanha nas relações entre os seus conterrâneos, na medida em que dizem que o jovem "não aprendeu bem o jeito de ser homem". Com efeito, ao usarem o termo de tratamento com Nguyaecüe, seus parentes, próximos ou distanciados, referem-se a ele como um tipo de "parente vazio", denotando a posição duravél de solteiro e, mais especificamente, a solteirice associada à ideia de infertilidade ou de não continuidade do parentesco.

Para Nguyaecüe, a posição de ambiguidade, associada à solteirice prolongada, gera o sentido de "desconfiança" na rede de socialidade local. Isso porque o seu processo de "virar mulher" - a fim de, com isso, poder "assumir seu namoro" com outro ticuna - "incomoda a muitos na aldeia".

1 Grifos meus. As conversas aqui apresentadas foram realizadas em momentos distintos da pesquisa, em abril e dezembro de 2013, em julho de 2016 e outubro de 2017. As traduções de termos e expressões ticuna usadas no texto contaram com auxílio dos colaboradores, usando-se também glosas por eles elaboradas.

2 O termo "caigüwaecü” aplicar-se-ia apenas às práticas sexuais envolvendo homens. Em ticuna, a expressão " $n g \ddot{u} e$ tügümagü” traduz práticas associadas às mulheres que mantêm intercursos sexuais com outras mulheres, porém referindo ao uso da vagina, não ao ânus. Conferir em Gregor (1985) e Fernandes (2013) correlatos linguísticos de ocorrências de práticas sexuais homólogas em outras paisagens ameríndias. 
Nesse cenário, mais do que tomar a clássica ideia clastreriana do "escândalo lógico" (Clastres 2003[1966]:127), mostrando o modo particular como as relações homoafetivas encontram lugar nas lógicas de socialidades indígenas, este artigo enfatiza o movimento de deslocamento das posições de gênero e as reconfigurações no idioma do parentesco provocado pela experiência de Nguyaecüe ao torna-se mulher. Para isso, partimos da premissa etnográfica de que ser "ngemã", solteiro, não parece representar um problema à Nguyaecüe, senão um momento "de se fazer mulher" e elaborar-se enquanto desposável.

Nesse sentido, o texto mostrará aspectos da transformação de Nguyaecüe em Nega, o nome elegido para portar enquanto paulatinamente altera não apenas sua perspectiva de gênero, como também suas posições no sistema formal de parentesco ${ }^{3}$. Com efeito, a solteirice questionada seria um nexo relacional que proporciona um momento de mudança na sua condição de alteridade interna, oportunizando atuar "igual aos demais parentes que casam”.

Sendo a solteirice uma posição por ele requerida - posto que não quer se casar no modo convencional, com uma prima cruzada, como orientam os "saberes ticuna das regras dos clãs e do parentesco antigo", e, como efeito da aliança conjugal, abrigá-la enquanto esposa -, Nguyaecüe assume, como estratégia, ser solteiro. Atua nessa posição reconhecida no idioma de relacionalidade ticuna, mantendo a estrutura, "seguindo as regras", ocupando, assim, uma posição intermediária e ambígua no jogo das alianças matrimoniais que negocia, enquanto espera "virar mulher".

Desse modo, argumenta-se que a passagem aqui descrita, de condição e estatuto de pessoa e parente, resulta para ele na (re)estabilização das relações de parentesco, conforme habita as normas, "colocando nelas o seu jeito". Nesse movimento, recria para si uma nova gramática relacional, habitando os domínios de socialidades femininos, nelas reelaborando suas condições às alianças, redesenhando suas posições políticas e morais na aldeia. Com isso, sua experiência deixa ver que as formas da sexualidade ticuna subsidiam as construções socialmente orientadas de gênero e parentesco, não estando a elas subordinadas (Castro 2015). Para entender como e em que condições se dá a transformação da posição de gênero masculino de Nguyaecüe para a posição feminina, seguimos o rastro de debates precedentes (Rosa 2015, 2016), buscando, então,

3 No decorrer do texto, as oscilações no emprego do pronome pessoal relativo ao interlocutor principal ocorre na medida em que sua própria narrativa se desloca nas performatividades de gênero, que o caracteriza e toma-se aqui como objeto de análise. 
nos aproximarmos das teorias ticuna acerca das relacionalidades que incidem sob os "muito jeitos" de estar no mundo e produzir parentesco, dessa vez, lançando luz à problemática do matrimônio, ou à sua ausência.

Para conduzir as leituras sobre essas experiências, ensaiamos aproximações à proposta de Butler (1990, 1993), para quem gênero, como categoria de análise, opera enquanto uma construção sócio-histórica e contingente. Dialogamos também com Strathern (2006), para quem o gênero conformase enquanto relações que operam como locus de provimento a modelos de relacionalidades e provoca pensar, em cada particularidade, como as fronteiras discursivas se estruturam e engendram classificações (Strathern 2005, 2016). Nessas perspectivas, destacamos que, ao nos remetermos à categoria gênero, ela está sendo tomada como um princípio de análise performativa, ocupando-nos em entender o que ela faz, o que comunica entre termos e contextos de relações que interligam homens e mulheres e eles entre si. Nessa esteira, ao descrever aspectos do processo de passagem de Nguyaecüe sobre a passagem de sua condição de solteiro para a de esposa potencial, e sua aquisição do gênero feminino, objetivamos evidenciar que, na própria instabilidade criada nessa relação de solteirice, temos a elaboração e o controle da diferença necessária à manutenção e à atualização da socialidade ticuna.

Nesse sentido, o caso de Nguyaecüe nos possibilita observar sua experiência cotidiana perante às normas do parentesco convencional, para conhecermos de que modos e em que condições se dá a passagem que o faz "virar mulher". Para tanto, mobilizase dois componentes nos conjuntos de ações e investimentos que o interlocutor faz na produção de um corpo sexualizado e da pessoa feminina: a adoção e o casamento. Tomamos essas articulações entre gênero e sexualidade enquanto expressão etnográfica do conceito relacional ticuna de parentesco, que engendra e atualiza os critérios e valores que circulam nos regimes de troca matrimonial e sistemas de alianças. Se a aquisição de gênero, nesse contexto, relaciona-se aos modos de saber produzir-se enquanto pessoa e parente através do exercício de incorporação das capacidades femininas ou masculinas, a sexualidade praticada pela interlocutora apresenta-se mutuamente como nexo performativo que agrega sentido ao processo que elabora para transformar seu corpo e ponto de vista masculino naquele assumido enquanto Nega. Dessa forma, o texto mostra os efeitos dessa passagem nos 
modos de (re)ex(s)istir da interlocutora e a transformação de sua solteirice em uma relação criativa de maternidade performativa enquanto possibilidade da produção de modulações no parentesco e de suas grámaticas de gênero.

\section{UM POUCO SOBRE OS MAGÜTA}

Menos conhecidos pelo etnônimo, os Magüta, "o povo pescado do rio", são tratados na literatura etnológica (e não apenas) usualmente pelo pronome exógeno Ticuna, ao qual aderem, e que foi a eles atribuído a partir do contato, ocorrido ainda no século XVII (Oliveira Filho 1988; Goulard 1998).

Os Ticuna são, atualmente, considerados a maior população indígena da Amazônia transfronteiriça, com aproximadamente $55 \mathrm{mil}$ pessoas no Brasil. São falantes de língua epônima e habitam localidades situadas às margens e aos interflúvios do rio Solimões, no sudoeste do estado do Amazonas. Seus territórios transfronteiriços, interseccionados ao Brasil, ao Peru e à Colômbia, são reconhecidos nos três países sobre os quais se justapõem, mantendo suas particularidades e distinções em termos linguísticos, organizacionais e de instituições indígenas (López Garcés 2003). No Brasil, estes territórios estão distribuídos em cerca de 30 Terra Indígenas, compostas por mais de 127 aldeias, de acordo com os dados publicados pelo Distrito Sanitário Especial Indígena (DSEI) do Alto Solimões, em 2018.

Esse ordenamento territorial é resultante de um continuado processo de territorialização, iniciado ainda no século XVII, quando ocorreram os primeiros registros de contatos dos Ticuna com as missões espanholas e portuguesas, em disputas pelas "terras descobertas" (Oliveira Filho 1988). Desde então, motivados pelos projetos de ocupação e expansão das frentes de exploração de recursos e mão de obra, as continuadas dinâmicas de deslocamentos ou "descimentos" (Faulhaber 1997) dos Ticuna, e de outros povos da região, os conduziram a habitarem às margens do Solimões, onde chegaram em definitivo após migrações das terras firmes, mobilizadas pelas fugas aos processos diversos de "correrias", estendendo suas territorialidades até a cidade de Manaus (Goulard 1998; Porro 1993).

A partir da década de 1940, com o declínio da economia da borracha, no alto Solimões, as mobilidades ameríndias seguiam-se em outros tipos de deslocamentos. A chegada do Serviço de Proteção ao Índio (SPI) buscou minimizar os fervorosos conflitos relativos à terra e à distribuição fundiária, tornando-se ele mesmo uma instituição civilizatória do Estado no projeto integracionalista, (re)educando os modos de vida indígenas para a agricultura, fixando-os em assentamentos (A. Lima 2015); também a igreja cristã, em 
diferentes instituições confessionais, atuou na região para conceder direitos sociais básicos, como a escolarização, em especial o letramento, implementando acessorias técnicas também no campo da saúde (Faulhaber 2003). Disso derivam os grandes aldeamentos Ticuna, resultados dos assentamentos no entorno dessas instituições, reivindicados e concedidos pelo Estado brasileiro, nos anos da década de 1980 e 1990, como parte das atuais Terras Indígenas Ticuna.

Assim, os processos de "fluvialização" (Goulard 1998) e, posteriormente, os de "territorialização" (Oliveira Filho 1988), ora em fugas das ações missionárias ora em retirada das instalações das empresas seringalistas na região, implicaram, como conta Nguyaecüe, a entrada "nos mapas da na'ane (território tradicional) das cidades, das aldeias, das fazendas de gado". Este processo expressou também novas territorialidades indígenas e recriou os modos de organização socioespacial: agora, como reiteravam os interlocutores, "somos os Ticuna do Brasil, os Ticuna do Peru e os Ticuna da Colômbia”. Nguyaecüe mesmo conta que seu avô, antes de falecer, assim como seu pai, lhe diziam que esses "jeitos de ser Ticuna" são diversos desde o "tempo da pescaria", quando se tornaram Magüta, "gente de clã com pena" (achi'igü) e as "gentes sem pena” (ngechi'igü). Conta o jovem que, desde os tempos dos ancestrais, "os pensamentos sobre o território vêm mudando" na mesma medida em que "as regras de fazer casamento certo", "o jeito de ser homem e o jeito de ser mulher" também. Contanos que os modos de "ser e se fazer Magüta" estão sempre se "misturando"; alterando-se, conforme vão "mudando e aparecendo novos conhecimentos, novos parentes, novos pensamentos nas vivências da pessoa no mundo".

Relatam os interlocutores que os Magüta surgiram enquanto povo, coletivo organizado de parentes, “tanü”, após uma série de infortúnios levados a cabo por um dos germanos criadores dos Ticuna, Yoi e Ipi. O segundo germano, descrito como travesso e sem juízo, cometeu incesto com uma de suas irmãs, Aicüna. Dessa ação resultou o "entristecimento" dos ancentrais, que passaram, por isso, a habitar outro patamar da cosmografia, dividindo a coexistência desses universos de socialidades, entre o mundo dos mortais, os “yunatü", onde vivem os Magüta e os demais povos, e o mundo dos imortais, dos “ü’ünegü”, onde habitam os demiurgos, e para onde encaminha-se cada pessoa Ticuna no processo posmortem, cumprindo seu devir, “ü’üne”. Para isso ocorrer, no entanto, é preciso seguir certas regras de convivialidades.

4 Ver Goulard (1998), para mais detalhes sobre a "fluvialização", remetendo aos movimentos de ocupação dos Ticuna em áreas às margens e aos interflúvios do rio Solimões, quando deixam de habitar as terras altas. 
Uma delas, "a mais antiga”, surgiu após o ato de incesto de Ipi para controlar os "namoros errados". Para refazer o mundo ticuna, salvaguardando-o de novos infortúnios, Yoi pesca o povo Magüta do rio, transformando cada peixe em um parente, atribuindo a eles clãs de pertencimentos, “cüẫ", para que não mais confundissem suas irmãs com esposas. Para criar os gradientes de distancimentos, Yoi deu a cada um que pescava um caldo para beber, cujo sabor identificado por quem o bebesse definiria seu grupo social. $\mathrm{O}$ universo de relações desse povo passa, então, a ser definido a partir do dualismo contido nos domínios opositivos que definem os pertencentes aos grupos daqueles com clãs associados aos animais com ou sem pena. No interior desse sistema, subgrupos se dispõem em um número não fechado de metades exogâmicas.

"Da bagunça, Yoi organizou o jeito do povo namorar e se fazer grupo de parente Magüta", relatava-me Nguyaecüe. Hoje, os interlocutores chamam esses princípios sociopolíticos de "regras das nações" ou "regra dos clãs". São esses dispositivos que passam a ordenar, desde os tempos prístinos, o regime de parentesco.

Estruturante ao sistema de aliança e conjugalidade, as dualidades complementares "do jeito de ser Ticuna" refletem-se nos modos de "casar certo/bem" e modos de "casar errado/ mal feito". Seguir as "regras das nações" configurase como um modo apreciado e "certo de casar". Nessas regras, definem-se as categorias de afins potenciais, os "primos certos de casar", e aqueles evitáveis, os primos paralelos ou germanos, "os parentes com quem se casa errado".

\section{3. "AS REGRAS DA CULTURA": O CASAMENTO CONVENCIONAL}

O tema da sexualidade entre os Ticuna é tratado desde a seminal monografia de Curt Nimuendajú (1972), não como objeto de análise, mas emergindo nas narrativas de criação do mundo como componente explicativo da noção de "womãtchi", cuja glosa é "gente de carne mal trançada/misturada" (Goulard 1998; Rosa 2015). Esse enredo narrativo nos conduz ao célebre assunto do incesto clânico, ou consanguíneo, e às estruturações do nexo dual e opositivo das práticas de socialidades indígenas. Dizem que aqueles que praticam "womãtchi" estão comentendo um tipo de "sexo malfeito", expressão indicativa de um dispositivo indígena da sexualdiade que funciona para controlar e criar técnicas e gestores morais contra tal condição antissocial, a exemplo da atuação de alguns pastores, agentes de saúde e familiares ou conterrâneos do interlocutor.

Ser "parente womãtchi", em certo paralelo, como discutido alhures (Rosa 2013, 2015, 2016), 
atualiza-se em formas outras de relacionalidades deletérias. Aquelas descritas como feitas por "parentes vazios", cuja improdutividade ao parentesco e à aliança convencional, e, por coextensão relacional, à pessoa ticuna, resultam

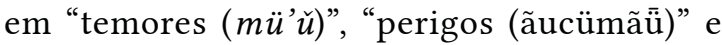
“entristecimento (ngetchã $\overline{\ddot{u}})$ ". Nesse repertório plástico de ações qualificadas como "sexo malfeito", aprendi que há formas distintas em que a sexualidade incopora-se à essa lógica e modula as formas de praticar o parentesco. Nguyaecüe sintetiza, informando que sexo malfeito pode ser explicado por "parente namorar homem com homem, mulher com mulher". Para ele e outros interlocutores, isso seria "um jeito de fazer casal de dois iguais, mas noutro jeito. Aí vira parente vazio. Igual aos womãtchi; igual aos solteiros. São chamados de 'parentes meia coisa, não bem dos pensamentos"”.

Enquanto ações de controle da diferença indígena contextualizadas nos "saberes dos antigos", "a história das regras das nações”, que dá origem ao dispositivo da sexualidade, tem como efeito central, nas atuais micropolíticas de parentesco ticuna, apresentar e reafirmar princípios gerais da linguagem pela qual os colaboradores comunicam sua sociologia relacional, especialmente interessados em decompor alguns conteúdos de termos de parentesco e relação. Nesse contexto de diálogos, observamos as lógicas organizativas que se abrem às linhas de afinidade, identificando aqueles a quem tratam de "tchaua'ta", os afins virtuais, glosados como "primos/as bons de casar". São ele/as os cônjuges preferenciais em contraste gradual com as linhas de consanguinidade apresentadas pelos "parentes pa'mai”, "os/as irmãos/ãs de nação/clã”, considerados pares "errados para casar", assemelhando-se entre si pelos graus de similaridades que os alocam como "irmãos" com inflexão de gênero, "tchaueya" e "tchauene", feminino e masculino, respectivamente.

O “método de classes” (Lévi-Strauss 2011[1947]) ticuna proposto na linguagem da "regra das nações" elucida, portanto, categorias sociocêntricas que ativam gradientes de aparentamento e posicionam os pares preferenciais para a aliança matrimonial. Também jogam luz às variedades de alteridades que, não estando a elas circunscritas, habitam às suas margens, assumem lugar de Outro. É sobre esses avessos da regra que versam as experiências de Nguyaecüe transformando-se em Nega.

A depender da graduação da afinidade, uma miríade de atores, saberes e modos relacionais se interseccionam ou se distanciam. Entre aqueles de fora, há alteridades não indígenas, ora tratadas genericamente enquanto “dü̈'gü i tcho' ’̈̈, " "povo dos Brancos”, e, em uma linha mais extrema e perigosa de afinidade, alocam-se os "awane", os inimigos. 
Nesse quadro referencial, as modulações nos gradientes internos destacam "patcha" como glosa genérica à palavra "parente". O emprego do termo de relação parece-me designar aqueles a quem se considera aparentado, podendo ser "parente de longe", mas passível de virar "patcha de verdade". Isso implica o sentido da proximidade real e do convívio, demarcando os limites performáticos e situacionais desses laços, a exemplo do que ocorre quando aqueles parentes que são Ticuna de outra aldeia, adotados ou cuja origem é colombiana ou peruana, "ficam perto, comem e riem juntos".

Nessa chave explicativa, "patcha" como a afinidade, no grau mínimo reconhecível para implicar laço de aparentamento, caracteriza, nos tempos e espaços das relações, uma sociologia intraticuna, no seio da qual aparece a semelhança antes do que a diferença, como se notou anteriormente (Taylor 1983; Albert 1985; T. Lima 1996), enquanto esquema relacional mais básico. No que nos interessa debater a seguir, ao falarse em "regra da cultura", Nguyaecüe enfatiza as "mudanças" nas normas.

O que aprendemos quando se passa a olhar como outros componentes vêm a integrar o sistema básico, opositivo e complementar, incorporando a ele, entre outros elementos, a sexualidade como fator operador das diferenças e das relações? Em que condições a sexualidade desviada de Nguyaecüe evidencia no "parentesco oficial” (Rosa 2016) processos de transformações semânticas, políticas e morais? $\mathrm{E}$, mais do que isso, os avessos do parentesco elaborado por Nguyaecüe, ao transformar-se em Nega, nos reclamam etnografias voltadas ao campo das experiências que projetam sentidos às estruturas e aos rearranjos orquestrados às regras, conforme as conjunturas (Carsten 2000; Schneider 1980).

Nguyaecüe afirma que, independente do "jeito do parente se fazer no mundo", a "mistura boa tem que ter diferença”. O que, na métrica do parentesco conjugal, convencional ou transformado, replica a ideia de que, para ter eficácia social como "casamento bem feito", as relacionalidades devem ser efetuadas entre partes diferentes na relação - corpos, fluidos, sexo, gênero, clã, metades, nomes -, reiterando a filosofia ameríndia, da qual os Ticuna que conheço são signatários, da centralidade da diferença e da garantia do bom distanciamento para a manutenção do socius e da própria identidade (Overing 1984; Héritier 1994; Coelho de Souza 2008). É nesse cenário que Nguyaecüe faz a passagem para Nega, e nos convida a conhecer em que condições isso se passa e que modulações provocam no parentesco que produz. 


\section{OUTRAS FORMAS DE HABITAR AS NORMAS: NGUYAECÜE, "MAS SÓ ATÉ VIRAR MULHER"}

Nguyaecüe é pertencente ao clã de côco de palma (arücüã) e habita a aldeia à beira de um igarapé que encontra o rio Solimões na temporada de cheia, entre novembro e julho. Nos meses de seca, chega-se à aldeia caminhando, cruzando por outra aldeia ticuna e um povoado mestiço, desde onde são alcançados os barcos e as lanchas para chegar à cidade de São Paulo de Olivença.

Até meados de 2017, Nguyaecüe pouco havia saído da aldeia, e quando o fez foi ao povoado vizinho, acompanhado por sua mãe e tias maternas, para compras de mantimentos, ajudando na tarefa de tradutor junto aos donos dos comércios. Em outras ocasiões, ele esteve em festejos da igreja e nas aldeias vizinhas. Nguyaecüe aprendeu, na escola bilíngue da aldeia, a falar português, mas pouco escreve, ao contrário do que faz na língua indígena. Como parte de sua "comunidade", ele frequenta a igreja Batista, comandada por pastor indígena desde os anos da década de 1980, quando a aldeia "ganhou autonomia"5.

Nguyaecüe destaca-se, ao lado de sua mãe, viúva, nas atividades de roçado. Diferentemente das rotinas dos demais jovens de sua idade, Nguyaecüe não aprendeu a pescar ou a caçar. Dedicou-se à arte da "roça e dos estudos". Um dos "derradeiros solteiros" de sua geração, com aproximadamente doze jovens de seu grupo extenso, todos já com matrimônio contraído e filhos feitos, ele, de outro modo, enquanto "espera para poder casar", mora com sua mãe, em um espaço rodeado por outras casas habitadas por suas duas irmãs mais velhas e o seu irmão caçula, todos também casados. Nesse contexto, ele dizia-me estar "virando mulher" e "aprendendo a fazer grupo de parentes".

De aparência bem juvenil, rosto arredondado, queimado do sol, com cabelos à altura dos ombros, de longos fios pretos, Nguyaecüe usava unhas curtas e sempre pintadas; trajava saias à altura dos joelhos, de corpo esguio; bastante tímido, porém "corajoso" e "curioso". Aos poucos, ele tomava confiança e ensinava-me que seus traços de timidez, em realidade, em nada diferenciavam-se do comportamento das demais mulheres na aldeia.

Tom de voz agudo e delicado, Nguyaecüe, como costuma se apresentar para evitar "problemas", compartilhava com elas as mesmas expressões de "jeito de mulher": olhar baixo e, ao falar, lançava a mão diante da

5 Sobre o contexto de evangelização entre os Ticuna, ver Macedo (1999). Neste trabalho, o autor contextualiza os processos de autonomia conquistados pelos Ticuna associados, entre outras coisas, ao acesso ao letramento e outros "benefícios" que a evangelização implicou. Especificamente a partir dos anos da década de 1980, todas as aldeias Ticuna evangélicas já tinham seus próprios pastores-parentes, sem haver mais a presença de missionários norte-americanos na função. 
boca. Conjugado a esses gestos, Nguyaecüe, para responder afirmativamente às mulheres, levantava as sobrancelhas - aos homens, além do gesto, há um som breve emitido, algo similar a um assovio, marcando a inflexão de gênero nas etiquetas cotidianas. Ele e outras parentas diziam que tais performances e traços estéticos seriam característicos do "jeito de ser mulher", aprendendo que tal "jeito" correspondia a um continuado fabricar da pessoa, por meio do qual relações se estabelecem, com demarcação dos domínios de gênero e aplicação das pedagogias moralizantes (Lea 2012; McCallum 2001; Belaunde 2015; Pissolato 2007, 2012). Ainda que assumisse a posição feminina e a adquirisse paulatinamente, ele hesitava, em certos momentos, em autonominar-se como Nega. Dizia-me que, para isso ocorrer, era preciso ainda percorrer alguns caminhos, "formando o pensamento de mulher, aprendendo mais a ser desse jeito, até conseguir virar mulher madura".

Nesse ínterim, ele contava que, "na regra mesmo da cultura", "diz as palavras dos antigos que mulher acompanha a canoa, não pesca; aprende a tecer e a fazer boa comida; os homens [aprendem a] caçar, a fazer as ferramentas”. As mulheres, seguia ele, "viram esposas, mães, cunhadas, tias, avós”. Em outro domínio relacional da gramática ticuna de construção da pessoa como extensão das modulações do parentesco e do gênero, Nguyaecüe mencionava que meninos, desde pequenos, vão aprendendo certas atividades, "certos saberes". De solteiros, eles "viram esposos, pais, tios, avôs", estabelecendo-se, nessa "feitura da pessoa", os "aliados” e também "criando parentes". Nessa lógica, "a pessoa vira madura, assim, como minha mãe”, dizia Nguyaecüe.

Isso de virar mulher, é como tomar
lugar no pensamento, no jeito de estar
aqui na vida, fazer o que as mulheres
fazem, assim, como ma'ma [mãe]
ensinava minha irmã. E foi nisso que
me fazia mais alegre. Não gostava
muito de estar no meio dos meninos
e aprender o que eles faziam, de pescar,
brincar de caçar bicho, de fazer canoa;
eu gostava de aprender da roça, de
como plantar macaxeira, fiar tucum
para rede, fazer esses cestinhos aí;
homem também faz cesto de roça, mas
tem cestinho bonito que mulher que
faz. Feio mesmo, vou contar, é esses
caigüwaecü, que são homens com
jeitos de mulheres não assumidos. Não
sabem o que querem, não viram gente
madura, ficam aí, como os loucos, os
palhaços, as gentes womãtchi da aldeia.
Eu queria que todos me vissem como
mulher e me dessem esse sossego, que
parassem de me chamar de parente
vazio, de meia coisa. Por isso, vou
virando mulher solteira para casar
certo. Casamento certo não tem a
ver como a gente namora [relações
sexuais] ou usa a vagina, o ânus ou
pênis. Isso é o jeito que o parente usa
a regra dos antigos para proibir meu
jeito de ser mulher e o casamento do
jeito que eu quero. Isso não vem dito
na regra dos antigos, lá fala nas nações.

Questões éticas e morais estão em jogo nessas classificações de parentesco, bem 
como os modos pelos quais a sexualidade opera modulando os gradientes, atualizando as estruturas através das estratégias (Madi Dias 2018; Butler 1990). A fala de Nguyaecüe parece evidenciar, por um lado, o parentesco e seu gênero enquanto produtos das relações e, de outro, e concomitantemente, a sexualidade como operadora dessas últimas. Assim, corroborando a suspeita de Castro (2015:510), a sexualidade, antes de ser subordinada, é ordenadora de relações. Destarte, o processo descrito por Nguyaecüe e pelos demais na aldeia revela a sexualidade enquanto vetor de valores e princípios polifônicos, expressos aqui pelo "uso confuso" do órgão sexual e dos decorrentes efeitos de uma prática sexual improdutiva, que o torna um "parente vazio". Ele ocupa esse estatuto por estar na posição de "caigüwaecü" e por não ter o casamento pretendido aceito, seguindo solteiro.

"No jeito do parente antigo", dizia Nguyaecüe, casava-se "primo do clã de buriti com a prima clã de mutum”. A troca exogâmica aparece novamente como uma forma geral do princípio de aliança, estabelecido desde os tempos prístinos, como vimos. Nesse escopo, sobre o que difere as posições e orifícios sexuais naquelas circunstâncias em que a jocosidade de sua posição lhe incomodava, Nguyaecüe apontava a reflexão para a questão da produção de uma situação de "sexo malfeito", e como isso se conectava aos "jeitos de ser homem e mulher":

Tem disso aí, das mudanças das
palavras, as chegadas de outros
pensamentos e jeitos de ser. Mas tem
gente que não gosta; tem parente que
ignora a gente, não deixa participar
de algumas atividades. Não quero ser
sozinho, por isso brinco nessa coisa
de virar mulher.

Nesse registro binário, Nguyaecüe chama atenção a dois conjuntos de relações que cerceiam seu modo de ser solteiro. Um deles é o componente heteronormativo da regra e dos termos empregados: "é marido (nate) e esposa (namâ). [...] Nessa versão dos parentes antigos não pode homem com homem ou mulher com mulher".

Curioso notar que Nguyaecüe, quando pretende assumir a posição feminina na etrutura de parentesco, em nada contradiz tal princípio sociológico da regra, pelo contrário. Seu esposo pretendido, na aldeia vizinha, pertence ao conjunto de metades compatíveis à aliança exogâmica. Mantém-se, assim, caso a conjugalidade se efetive entre eles, a "regra da cultura". Ademais, Nguyaecüe já tem casa e uma roça iniciada à sua espera na aldeia vizinha, caso não se sinta à vontade para ficar. Na aldeia do pretendente, também o tratam como "caigüwaecü", onde ouvi dizer que, enquanto não "ajuntar e viver como casal de verdade, não é esposa e esposo". Outro aspecto que ele comentava 
estar associado ao seu transformar-se "devagar" em uma mulher está relacionado aos efeitos deletérios que sua atuação feminina provoca naqueles de posturas mais ortodoxas (sejam elas religiosas, políticas ou geracionais), que, mesmo no tom de deboche, constituem-se como formas de sanções, onde reside seu incômodo.

O dispositivo da sexualidade, quando relacionado às questões de "sexo malfeito", nos conduz aos entendimentos do que a experiência aqui descrita objetiva evidenciar nas atualizações das gramáticas do parentesco e da pessoa, assim como da produção de um corpo generizado ticuna. Falar sobre, ou deixar-se ver nestas relações de “mesmo sexo", lançava sobre Nguyaecüe espaços de controles a eventuais infortúnios agenciados pelas condutas sexuais desviantes não negadas por ele. Ao seu modo, não mais como parente “womãtchi”, mas como “caigüwaecü”.

Estes universos ticuna, em suas cosmopolíticas próprias, não deixam de dialogar com facetas da "sociedade que fala sobre sexo" (Foucault 1988). O faz tomando as palavras "dos antigos" ou todas aquelas "novas chegadas" como mecanismos que capilarizam as relações de poder e saber, ampliando e borrando referentes, não a partir de uma figura centralizada, soberana, senão de uma malha de discursos-saberes visíveis em muitos hologramas, como os dos agentes de saúde, dos pastores e de outros parentes evangélicos ou, ainda, de algumas figuras de lideranças políticas, como relatou o jovem.

É precisamente nesse aspecto que as relações de gênero e sexualidade se engajam e alimentam os dilemas do parentesco aqui descritos. O esforço de Nguyaecüe parece evitar criar uma analogia com o que Overing (1984) denominou de "vácuo classificatório" e restabelecer suas socialidades criativamente. O desalinho no modo de ser de Nguyaecüe, enquanto solteiro e "caigüwaecü”, suspende temporariamente as convencionalidades, daí as decorrentes piadas e acusações de "dar o golpe na cultura". Algumas figuras de "autoridade" política local costumavam repreender as atitudes do jovem, acusando-o de "ser um jovem sem juízo"; "seu jeito de ser dá o golpe na cultura”. Outros indígenas zombam e a ele lançam "ofensas", “palavras feias, piadas". Houve pedidos para ele frequentar a igreja ou o posto de saúde da aldeia, bem como para que cortasse o cabelo "e vestisse no jeito de homen, igual documento".

Se a força modeladora e homogeneizante do discurso dessas figuras controladoras é "consertar" coagindo, Nguyaecüe responde-os no encalço político, pela repetição, tornando suas atuações como mulher um exercício de elaboração de si enquanto uma "parenta em formação": "pinto unha, deixo cabelo grande, corpo com saia, com jeito das mulheres; namoro igualzinho elas, porque 
sou como elas, amanso eles [homens]”.

Propondo o corpo generizado como relação e foco de poder, parece-me que, ao insistir na diferença performática de seu gênero feminino em construção e de sua sexualidade diferenciada (Butler 1990, 1993), Nguyaecüe, sua mãe e germanas visam convencer do contrário - "amansando" - aqueles desgostosos que passavam a "vigiar" os namoros e suas relações cotidianas para "fofocar" ou fazer "piadas".

"Virar mulher" seria um ato ou um modo de habitar o contexto de instabilidade, tornando-o apenas um momento transitório, dotando-se de poder e agenciando novas relações. O modo de se tornar e assumir a perspectiva feminina dessa interlocutora parece aproximar-se, como sugere Butler, a partir de Austin (1962), de atos que, ao serem vistos, "fazem existir o que dizem". Transpondo a proposta desses autores ao contexto deste artigo, podemos pensar que os "namoros" e as práticas sexuais ilícitas, desviantes ou transgressoras desse interlocutor, e a sua condição estratégica de solteirice prolongada, seriam - assim como os modos de atuar daqueles que o desaprovam - ações performáticas reveladoras das disputas de forças e dos referentes coexistentes que orbitam no entorno dos múltiplos regimes de verdades acerca dos modos de estar no mundo ticuna.

Assim, a sexualidade funcionaria enquanto ordenadora do parentesco e das relações de gênero que o constituem. É nessa arena que são criadas realidades (discursos) e materialidades (corpos/ pensamentos/conhecimentos/jeitos) geradoras das noções êmicas de domínios femininos e masculinos de ação social, desde os quais emergem os muitos "jeitos de ser" mulher, inclusive o da interlocutora, e os "jeitos de ser homem" ticuna, que parecem se confrontar e reafirmar, no limite, a necessidade da diferença na constituição da socialidade e do parentesco, conforme afirmado por ela.

Para entendermos essas dualidades constitutivas da pessoa e que importam ao parentesco e à sexualidade ticuna, a expressão "na nge'â'ê" descreve um conjunto de relações generizadas que resulta, de acordo com as narrativas da interlocutora, na maneira por meio da qual "a gente diz o jeito de ser mulher”.

\section{VIRANDO MULHER}

Algumas mulheres na aldeia haviam qualificado Nguyaecüe como solteiro e, ao saberem que eu estudava ali as formas do matrimônio, logo enunciaram: "não casa esse daí", justificando que ele não saberia sobre o assunto. Para elas, Nguyaecüe era "ngemâ" (solteiro) e "na nge'â'êe" (com jeito de mulher). Elas diziam-me, quando estava distante dele, que a "pergunta" certa para lhe fazer era "de esposa”, esta ele saberia. Mais do que isso, Nguyaecüe, ao explicar-me, logo que o conheci, que ele era uma 
"quase mulher", soube ensinar-me como se produzia, desde seu ponto de vista, a relação para fazer-se enquanto "pessoa com jeito de mulher". Para isso, falava-me de suas ações para tornar-se "mulher solteira e madura”. Com ela e outros da aldeia, aprendi que "na nge'â'ê", e seu reverso simétrico, “na yâtüã'êe são expressões que desenham os campos de socialidade de gêneros ticuna

\begin{abstract}
na nge'ãẽé é como a gente diz assim o jeito de ser mulher e na yâtüã'ê como a gente diz na gíria ticuna o jeito de ser homem. [...] Isso tem de ver assim com o jeito da pessoa querer estar no mundo, fazendo coisas como mulher e fazendo coisas como homem, de formar o pensamento dela nisso. Aí a pessoa vai virando, ou um jeito ou outro. Isso se aprende de pequeno. A pessoa nasce, vai virando gente, vai virando homem, vai virando assim mulher [...]. Os pensamentos não nascem prontos, vai formando, vai fazendo a pessoa. Assim, como diz na gíria do ticuna: ñaãü ni mã $\tilde{u}^{7}$. Isso é assim o jeito, a pessoa se faz, que se vive. Não é diferente daquele caldo dos ancestrais que ia fazendo a pessoa no jeito do clã dela. No jeito de ser homem ou mulher é como isso, vai ganhando sabor e saber sobre o que a pessoa é conforme ela vai vivendo e aprendendo. Nasci de um jeito e fui me fazendo noutro.
\end{abstract}

O relato ora exposto traz descrições de modos de agir no mundo relacionados aos repertórios de conhecimentos, "os pensamentos", "os saberes", que orientam ações e regimes de condutas éticas refletidas em estéticas singulares, em diversos campos de atuação do parentesco. Cada jeito de ser, e as suas pluralidades internas, conforma-se no "mã ’ü", "aquilo queé a pessoa”; uma noção, ao mesmo tempo, indicativa da pessoa compósita ameríndia, e por suas ações intensionarem a outrem, é também um agente (Strathern 2006). O “mã ’ü" manifesta-se enquanto locus de relações e é produzido sob os dualismos necessários aos esquemas de socialidades ticuna. Um corpo social que é particularmente construído e reconhecido, dotado de estatuto de mulher ou de homem, de esposo ou esposa, implica diretamente percebê-lo como resultado dos fluxos de socialidades que organizam a vida social, envolvidos na produção, na reprodução, na distribuição e na troca, conjugal ou não.

O que descrevem os interlocutores segue o mesmo aporte relativo à pessoa ticuna proposto por Goulard (1998, 2009) e Santos Angarita (2014). Para esses autores - o segundo Ticuna -, o “mã'ü” manifesta-se como locus de relações generizadas e produzidas no antagonismo necessário aos esquemas de socialidades, troca matrimonial, pertencimento clânico, roteiros rituais, domínios de gênero, seres mortais e imortais, irmãos míticos, solteiro etc. Tal estado anímico adquire materialidade relacional dotada de gênero por meio das filosofias de aprendizagem ticuna, que enfatizam e

7 Expressão que, neste contexto de narrativa, poderia sintetizar um conjunto de valores e afetos correspondentes aos jeitos positivados e gerativos de efeitos relacionais sobre si e daqueles com quem se convive. 
estimulam a aquisição de um 'gênero', em um dos dois registros reconhecidos: "jeitos de homens e jeitos de mulheres".

Retornando à temática do parentesco para a interlocutora, certa vez perguntei a ela se virava mulher para poder casar. Ela respondeu afirmativamente e complementou que, ao "virar mulher reconhecida", queria "sossego" e poder casar, abandonando a posição de ambiguidade, findando, com isso, as "piadas". Algumas delas se referem claramente à sua sexualidade e identidade de gênero. Elas lançam sentidos à sua instabilidade quando minha interlocutora era vista como Nguyaecüe: “ei, “caigüwaecü”, já virou mulher?"; "ei parente, vai casar com meu irmão?”; "caigüwaecü, vai aprender a pescar ou seguir na roça?", foram algumas colocações citadas por ela, dizendo-me, com o mesmo tom agudo e delicado de sempre: "aqui na aldeia, o pessoal bagunça comigo porque não caso. É como ter vontade e não poder, sabe? Aí viro solteiro 'caigüwaecu”'.

Para ela, tal situação, apesar de "triste", não era um "problema". Nesse sentido, a interlocutora me disse algo sobre os efeitos reversos dessas afecções negativadas que sua condição de solteirice mobilizava para outrem:

Sou assim, no pensamento de mulher que veio feito no pensamento, no jeito de corpo de homem. Me faço como mulher, quero casar com homem. Tenho nome de homem na língua, isso a gente muda, como fiz no português. Sou parente fraco, como dizem. Alguns não gostam do jeito que eu namoro, falam feio, que é um tipo de sexo malfeito, que minha vagina tá no lugar errado, mas a confusão é deles. [...] Sou assim, um parente que nasceu homem, se fez no jeito de mulher. Aí, falam de eu ser parente vazio por isso daí, de não fazer bem às convivências.

Isso parece-nos remeter à ideia de que as relações sexuais entre os Ticuna que conheço operam como princípio ordenador das relações e, no limite, compõem, de forma presente, um quadro de oposições mais amplo que sustentam a continuidade da estrutura do próprio grupo, conectando-se, portanto, aos princípios de construção da pessoa e do parentesco. Revela-se, neste contexto, o problema das avaliações deletérias a propósito do "jeito" afeminado da interlocutora, com base em regimes de conhecimentos que revelam corpos que importam, mais ou menos, ao idioma do parentesco convencional aos Ticuna. Isto é, aquele "feito no jeitinho de homem com mulher".

A sexualidade desviante da interlocutora é questionada porque está visibilizada, e, suspeitávamos juntas, por isso problemática. "Se eu fosse como o outro parente que também gosta de namorar com homem", seria menos problemático, "ninguém ia ver e rir". O tal parente "fica quieto", mora com outro "caigüwaecü", que diz ser "só seu primo de longe", ele é de outra 
aldeia e diz não ter família. Eles residem no caminho que dá acesso à roça, distante das casas centrais da aldeia.

A interlocutora contextualizava que, nesse espaço periférico, o casal vivia "sossegado", explicando a diferenciação entre eles, afirmando que tal parente "gosta de ser jeito de homem, não quer ser mulher, aí fica dois homens. Isso é feio, isso é parente vazio". A despeito de saber que a estratégia do "disfarçar" a sexualidade e a identidade de gênero desviante lhe garantiria "sossego", assim como esses primos performáticos o fazem, a interlocutora opta por outro caminho. Explicita sua condição feminina, reivindicando para si o tratamento enquanto Nega, e não mais como Nguyaecüe, criando meios de re(e) $\mathrm{s}(\mathrm{x})$ istir entre os seus parentes, em conformidade com as "regras da cultura".

De que forma, então, para nos encaminharmos ao final deste texto, a interlocutora busca driblar esses dissensos e produzir um lugar social reconhecido de mulher?

A passagem de Nguyaecü e sua posição ambígua e incômoda de "caigüwaecü" para a aquisição do estatuto de "solteira" se dá mediante a alguns processos modalizantes:

Mamãe é valente. Espia como a gente faz: eu estou mais para a filha do que para filho, sabe? Já faço coisas que minha irmã faz na vida dela, faço como ela fazia quando vivia aqui com a gente antes de ir embora com o marido dela.
[...] Faço assim, as coisas, as obrigações das mulheres: de roçado, limpar a casa, limpar roupa no rio. Não vou pescar, não, como fazem meus primos. Isso é coisa de homem [...], eu não faço isso. Não aprendi disso daí. Eu tenho terçado, pau de fiar rede e gosto de fazer isso, de ir para roça, de estar aí fazendo uns peixes assados, proseando e fiando tucum. Vou fazer curso e ser professor. Só que isso não me deixa respeito aqui. Falam essas palavras feias, de que sou mais fraco. Sou nada. Sei assim...é coisa de sentir aqui [com a mão, toca em várias partes do corpo]. Se eu fosse fraca, ia ter vontade de ir me embora daqui. Fazia isso, como os parentes aí da outra aldeia. Ficam tristes, se vão [suicidam-se]. Não faz caso disso, não. É como aqueles irmãos, filhos do Fulano, o cantor dos cultos, dos bailes. Ele também não se ajunta, quer homem, como eu. Ele tem jeito de homem. Aí, mora com o irmão casado, solteiro de verdade. Minha vida é disso... vou aprendendo a ser boa filha, de saber bem no jeitinho da ma'ma como se fazer madura. Ela fez parentes, eu vou aprendendo, um dia pego para criar a filha da minha irmã. Fui eu quem pegou [fez o parto] ela, mas não fui eu quem cortou o umbigo. Isso que faz são as tias, eu só ajudei ela a parir la no mato, como fazem as mulheres maduras.

Seguindo a conversa, comentei com a interlocutora sobre o que aprendia a respeito de ser solteira. Buscando entender os processos e os efeitos nas relações que ela praticava, lhe digo que, mesmo assumindo a posição social de mulher, engajando-se em redes de socialidades, criando para si relações e domínios femininos de ações, forjando um lugar de legitimidade, por estar mais próxima ao "jeito de ser mulher" convencional, seguiria "solteira", situação que talvez não modificaria seu estatuto de "parente vazio", relacionando-se à esterilidade reprodutiva. 
Ela respondeu:

Sei disso. Mulher solteira é feio também, porque não faz parentes, não tem mais aliados, esposo; fica sozinha no mundo; não faz vida de convivência, como diz. Mas é só um momento, até conseguir casar. De mulher solteira eu já tenho meus amantes (amare). Minha roça tá feitinha. Quero ser mulher de verdade, aquela parenta de quem não riem.

Após um ano sem visitar a interlocutora, em 2017, soube que, entre seu grupo familiar extenso, todos passaram, "oficialmente", a tratá-la por "Nega", apelido que ressalta a passagem do estatuto de gênero sendo efetivado, afetando, por consequência, a forma de tratamento. Quando estão entre si, a mãe de Nega a chama de filha, igualmente ao que faz com as demais "filhas de paridez", isto é, aquelas que "nasceram com jeito de mulher". Sobre o filho, que agora é filha e chama-se Nega, dizia-me a senhora de 58 anos, quando a reencontrei na cidade, haver "chegado ao mundo homem, mas foi virando filha". Ela dizia-me, ainda, que Nega "está mulher madura, está já ma'ma [mãe] e vai casar”.

\section{AS MODULAÇÕES NO PARENTESCO: A MATERNIDADE PERFORMATIVA}

[...] Só que não nasce filho da minha vagina diferente. Já estou mulher e assumindo o casamento com o Fulano. Eu vou ser mulher casada e ma'ma: “ngue'e nguete'e rü ngue'acüe" ${ }^{8}$. Não $p a ' p a$. Se o problema do pensamento desses parentes mais do modo antigo é fazer casamento para ter parente, dou o golpe, pego [adoto] criança e viro isso aí, ma'ma. Viro mulher com filho, madura. [...] Isso de casar, eu dou um jeito. Se não me quiserem por aqui, me vou para aldeia do meu amor.

Uma vez reconhecida enquanto mulher solteira, para torna-se "mulher madura" e desposável, restava a Nega o desejo de torna-se ma'ma. Dizia-me que o "pegar filho de outra mulher", uma prática de adoção aceita, garantiria a si mesma o domínio de socialidade feminino e ainda a produziria como mulher, cujos atributos confeririam maturidade e "respeito" para a efetivação de uma aliança conjugal.

Minha irmã se foi embora para a casa do marido dela, fica aqui próximo. Ela tem dois filhos desse marido dela, já vem outro aí. Posso trazer um para cá, já disse para ma'ma isso aí. Ela disse sim, pega para gente ir criando até eu ir para casa do marido. Ela disse assim, esse curumim terá três ma'ma. [...] Assim, trago para casa, faço filho meu: ensino, crio, tudinho, sei bem como fazer isso das ma'ma. Aí no papel, se precisar disso aí, de documento de vacina, a gente coloca que é filho feito por eles [irmã e cunhado]. Eu fico de ma'ma de criação, assim, não de nascimento, mas de feitura na convivência. Assim é na lei do ticuna, pode disso. Tem no'é [avó] que faz isso. Como na casa onde a senhora mora, quando está na aldeia. Lá, tem os netos da Fulana, tem não? Não têm $m a$ 'ma esses curumins, quem criou foi a no'é [avó] deles, foi não? Aí, acho que, se fizer como ela, eu também viro mulher madura, viro não? É o meu plano, assim, a minha vontade. Vamos ver o que acontece, né?

Casar é efeito e estratégia secundária no seu roteiro

8 ngue'e nguete'e rü ngue'acüe seria a expressão, em ticuna, que traduz mulher não casada com filho/a, enquanto seu contrário simétrico seria yatü ya nguemacü ngueacücü. 
de dupla alteração que a experiência de Nguyaecüe em "passar a ser" Nega nos mostra. A primeira delas situa-se na passagem de um tipo de pessoa social (mulher) para um tipo de parenta, "vazia/solteira" ou "casada", cada qual com implicações específicas na atribuição de estatutos e status na aldeia. Enquanto parenta vazia, o cuidado de Nega volta-se, pareceme, para a manipulação do corpo e das dinâmicas de relacionalidade que sua corporalidade generizada envolve nos vínculos afetivos e práticas sexuais que experiencia, avaliados desde o lugar do casamento ticuna e dos olhares do sistema formal de alinça, como agenciamentos despotencializados, aos contornos de uma economia da pessoa (corpos) e do parentesco. Essa condição, lembra Nega, a torna pessoa "fraca".

Nega dizia que, quando era Nguyaecüe, o seu incômodo relativo ao tratamento recebido como caigüwaecü residia em seu significado mais genérico, "aquele homem que faz sexo pelo ânus" e, com isso, descrevia o sentido pejorativo, remetendo-se à sua improdutividade ao idioma do parentesco. Ao entendermos os motivos para o rechaço daquela condição "confusa" atrelada ao "seu jeito de ser mulher", conseguimos apreender, afinal, que, ao assumir o processo de "virar mulher", Nega evitava sua associação às variações ticuna de "relações falsas" (Gow 1989:574).

Por isso, ter filho para ter condição de atribuirse a si mesma a posição de " $m a$ 'ma", para Nega, essa ação lhe daria acesso a possibilidades de re(e)s(x)istir nas normas, perfomatizando as lacunas provenientes de seu corpo sexualizado e generizado, mas improdutivo a certos fluxos do parentesco esperado. Para ela, especialmente, essas relações em conjunto produzem lugares e reconhecimentos específicos; a fazem enquanto pessoa com gênero socialmente acolhido, desvinculando-se, pois, do lugar de ambiguidade da solteirice estratégica.

\section{CONSIDERAÇÕES FINAIS}

As experiências de Nega mostram-nos percepções sobre a sexualidade indígena não fixada, $a$ priori, em características dos dimorfismos biofisiológicos, ou encerradas nos dualismos já conhecidos, sendo, dentro deles, subordinados a outros componentes da estrutura. Diferentemente, tais experiências de "virar mulher, mãe e esposa de alguém” nos conduzem à abertura de novos campos dialógicos, ampliando as perspectivas de compreensão dessas relações no quadro referencial dos próprios indígenas.

Como Castro (2015) e Belaunde (2015) indicam, em síntenses recentes, se, por longo tempo, certos pressupostos analíticos de algumas teses etnológicas, e da antropologia de um modo mais geral, reconheceram os domínios de gênero centrado nas relações - ou comportamentais ou econômicas da sexualidade transversalizada pelas leituras estrutruturalistas dos 
modelos de troca -, para entender sua simbologia dentro de regimes relacionais, trabalhos mais recentes (Cariaga 2015; Madi Dias 2018; Otaviano 2017; Ribeiro 2019) têm mostrado novos meios de expressar o que se vem descrevendo como argumento central neste texto, qual seja, parentesco, sexualidade e gênero são conjunturas relacionais, agem sobre as estruturas, remodulam referentes, deslocam as conformidades de gênero. E, talvez, mostrem que o avesso do parentesco contido nessas experiências menos ordinárias das etnografias revela que a fixação etnográfica por ver modelos de trocas funcionando nos nublou os olhares para outras possibilidades de ser ticuna.

Desse modo, a intersecção proposta aqui entre dispositivos da sexualidade indígena e o gênero do parentesco ticuna opera, do mesmo modo que a política ou a conversão, como um dos novos eixos para pensarmos sobre as formas através das quais alteridades tomam lugar nas socialidades e colocam em marcha atualizações nas normas, provocando modulação no regime de parentesco.

Sobre o princípio corporal de toda pessoa ticuna, diz a mãe de Nega: "não interessa se no jeito de mulher ou de homem, nosso jeito de ser parente e de se fazer assim, homem e mulher, se faz nessas vivências também, nas regras e nas mudanças de palavras, de saberes". E, por fim, ela mesma classifica instigantemente os valores contingentes constituintes dos regimes de classificação das pessoas e dos parentes, quando a sexualidade e o gênero ganham espaços analíticos: "a vagina da Nega fica no lado errado [risos] de fazer mais parentes".

Deixando de ser funcional ao parentesco convencional, a sexualidade da interlocutora, dita por alguns como "confusa", pôde, simbolicamente, alterar o sentido do "sexo malfeito" em práticas legitimadas de compor um campo de ação feminino. Assim, não apenas a posição ambígua e desvalorizada de solteira é transformada nas conjunturas, na medida em que a condição de infertilidade também se torna reversiva. Com apoio de sua mãe, germana e germanos, Nega propõe usar seus orifícios pelo prazer, e não "pela regra".

Assim, seu "jeito de ser" reflete indicadores de algumas posições relacionais possíveis enquanto parente, que, situacionalmente, podem modificarse em proveito de um bem coletivo, sem perder a dimensão das "vontades" individuais. Argumenta-se, pelo exposto, que o parentesco proposto por Nega segue criativo à socipolítica nativa, de outro modo, "colocando seus jeitos nas normas". Nos revela que relações não maritais, mediadas pelas problematizações de sexualidade, compõem conjuntamente termos vocativos, descritivos das práticas e dos valores agregados a elas, circunscrevendo pessoas como parentes de algum "jeito”, com seus qualitativos respectivos: "fraco", "vazio", "errado", "solteira”, “caigüwaecü”, "ma'ma”, "nate" ou "namầ". 
Fica claro, ainda, que a dualidade entre os domínios de relações femininas e masculinas é central e talvez estruturante às formas de socialidade ticuna, como indicam as narrativas míticas de crianção do mundo Magüta. Nesse sentido, analiticamente "jeitos de ser homem/mulher" desvelam uma sorte de capacidades agentivas providenciadas, reguladas, perfomatizadas e atualizadas nas pedagogias do fabricar parentes e pessoas (Hugh-Jones 1979; Lagrou 2007; McCallum 2001; Rubio 2004), a exemplo da troca de nomes e termos de tratamento, como fizera Nega.

Neste ponto, voltamos ao problema enunciado no início deste texto pela interlocutora de que certos modos de atuar sexualmente convertemse em dilemas morais e políticos. Observamos que isso ocorre porque seus modos de exercer a sexualidade não se mostram produtivos aos ideais de convivialidade, entre os quais o casamento é central e cujos alicerces situam a "feitura" dos parentes "bem feitos" como premissa que envolve e legitima os domínios de gênero, o vínculo conjugal pretendido e as potencialidades de alianças. Como vimos, Nega corrobora a suspeita de que estar sozinho, no sentido de não estar casada, elimina vetores de interações.

No verso disso, ela cria condição de re(e)s(x)istir quando estrategicamente performatiza sua identidade de gênero e estatuto de mulher madura, propiciando um intervalo criativo à elaboração de si em outro domínio de sociabilidade. A diferença propagada por sua instabilidade caigüwaecü é transformada em um campo de relações valoradas no regime de moralidades do parentesco convencional. Ela altera-se. Afinal, como pontuava: "dois iguais não fazem parentes", relembrando os princípios gerais da filosofia ameríndia da presença da diferença como meio à existência do social (Overing 1984). A relação criativa de maternidade performativa enquanto ações de modulações no parentesco de Nega nos mostra que, assim como gênero e parentesco configuram-se a partir de atos performáticos (Carsten 2000, 2004; Gow 1991), a sexualidade atua organizando a percepção das relações em uma conjugação, como lembra Madi Dias (2018:45), entre estrutura e estratégia.

Portanto, se há dois domínios de relações de gênero estabelecidos, "entre homens e mulheres", há, contudo, diferentes modos de exercê-los. A partir dessas proposições, finaliza-se o artigo, sugerindo-se que essas interlocuções estão pontuadas em uma sorte de imagens relacionais que conformam solteirices problemáticas em teorias locais de gênero enquanto experiência social (Strathern 2006; Gonçalves 2001; Lasmar 2005).

\section{AGRADECIMENTOS}

Esta pesquisa foi realizada com fomento do Conselho Nacional de Desenvolvimento Científico e Tecnológico (CNPq). Agradeço aos pareceristas pelas contribuições, bem como agradeço a toda a rede de interlocução. 


\section{REFERÊNCIAS}

Albert, B. 1985. Temps Du Sang, Temps des Cendres. Représentation de la maladie, système rituel et espace politique chez les Yanomani du sud-est. Tese de Doutorado. Laboratoire d'ethnologie et de sociologie comparative, Universitéde Paris X, Paris.

Austin, J. L. 1962. How to do things with words. Cambridge: Harvard University Press.

Belaunde, L. 2015. O estudo da sexualidade na etnologia. Cadernos de Campo (24):399-411. DOI: https:// doi.org/10.11606/issn.2316-9133.v24i24p399-411.

Butler, J. 1990. Problemas de gênero: feminismo e subversão da identidade. Rio de Janeiro, RJ: Civilização Brasileira.

Butler, J. 1993. Bodies that matter: on the discursive limits of "sex". New York, NY: Routledge.

Cariaga, D. E. 2015. Gênero e sexualidades indígenas: alguns aspectos das transformações nas relações a partir dos Kaiowa no Mato Grosso do Sul. Cadernos de Campo (24):441-464. DOI: https:// doi.org/10.11606/issn.2316-9133.v24i24p441-464.

Carsten, J. 2000. Cultures of relatedness: new approaches to the study of kinship. Cambridge/New York: Cambridge University Press.

Carsten, J. 2004. After kinship. Cambridge/New York: Cambridge University Press.

Castro, A. O. 2015. Desejo e prazer: um aspecto da sexualidade entre os Karitiana. Cadernos de Campo (24):505-523. DOI: https://doi.org/10.11606/issn.2316-9133.v24i24p505-523.

Clastres, P. 2003[1966]. O arco e o cesto, in A sociedade contra o Estado, pp. 117-144. São Paulo: Cosac \& Naify. 
Coelho de Souza, M. S. 2013. Porque a identidade não pode durar. A troca entre Lévi-Strauss e os índios, in Lévi-Strauss: leituras brasileiras. Organizado por R. C. Queiroz e R. F. Nobre, pp. 265-300. Belo Horizonte: Editora UFMG.

Faulhaber, P. 1997. Estrutura fundiária e movimentos territoriais no Médio Solimões. Boletim do Museu Paraense Emílio Goeldi, Série Antropologia 3(1):79-98.

Faulhaber, P. 2003. Processos jurídicos, ação corporativa e etnopolítica Ticuna no Brasil. Arquivos do Museu Nacional 61(2):61-70.

Fernandes, E. R. 2013. Ativismo homossexual indígena e decolonialidade: da teoria queer às críticas two-spirit. Anais do Encontro da ANPOCS 37:1-29.

Foucault, M. 1988. História da sexualidade 1: a vontade de saber. 15. ed. Rio de Janeiro: Edições Graal.

Gonçalves, M. A. 2001. O mundo inacabado: ação e criação em uma cosmologia amazônica: etnografia pirahã. Rio de Janeiro: UFRJ.

Goulard, J.-P. 1998. Les genres du Corps: conceptions de la personne chez les Ticuna de haute Amazonia. Tese de Doutorado, Departamento de Antropologia e Etnologia, École de Hautes Etudes em Sciences Sociales, Paris.

Goulard, J.-P. 2009. Entre mortales e inmortales. El ser Ticuna de la Amazonía. Lima: Centro Amazónico de Antropología y Aplicación Práctica (CAAAP)/Instituto Francés de Estudios Andinos.

Gow, P. 1989. The perverse child: desire in native Amazonian subsistence economy. Man 24(4):567-82. DOI: http://dx.doi.org/10.2307/2804288.

Gow, P. 1991. Of mixed blood: kinship and history in Peruvian Amazonia. Oxford: Claredon. 
Gregor, T. 1985. Anxious pleasures: the sexual lives of an Amazonian people. Chicago: University of Chicago Press.

Héritier, F. 1994. Les deux soeurs et leur mere: anthropologie de l'inceste. Paris: Editions Odile Jacob.

Hugh-Jones, C.1979. From the milk river: spatial and temporal processes in Northwest Amazonia. Cambridge: Cambridge University Press.

Lagrou, E. 2007. A fluidez da forma: arte, alteridade e agência em uma sociedade amazônica (Kaxinawa, Acre). Rio de Janeiro: Topbooks.

Lasmar, C. 2005. De volta ao Lago do Leite: gênero e transformação no Alto Rio Negro. Rio de Janeiro: NUTI.

Lea, V. 2012. Riquezas intangíveis de pessoas partíveis: os Mebêngôkre (Kayapó) do Brasil Central. São Paulo: Editora da USP/FAPESP.

Lévi-Strauss, C. 2011[1947]. As estruturas elementares do parentesco. São Paulo, SP: Vozes.

Lima, A. C. S. 2015. Sobre a tutela e a participação: povos indígenas e as formas de governo no Brasil, século XX/XXI. Mana 21(2):425-457. DOI: http://dx.doi.org/10.1590/0104-93132015v21n2p425.

Lima, T. S. 1996. O dois e seu múltiplo: reflexões sobre o perspectivismo em uma cosmologia tupi. Mana 2(2):21-47. DOI: http://dx.doi.org/10.1590/S0104-93131996000200002.

López Garcés, C. L. 2003. Etnicidad y nacionalidad em la frontera entre Brasil, Colombia y Peru. Los Ticunas frente los processos de nacionalidade, in Fronteiras, territorios e metaforas. Compilado por C. I. García, pp. 147-160. Medellín: Instituto de Estudios Regionales/Universidad de Antioquia. 
Macedo, G. M. 1999. A conversão cristã e a identidade Ticuna: a trajetória de Campo Alegre. Amazônia em Cadernos 5:175-194.

Madi Dias, D. 2018. O parentesco transviado, exemplo guna (Panamá). Sexualidad, Salud y Sociedad (29):25-51. DOI: http://dx.doi.org/10.1590/1984-6487.sess.2018.29.02.a.

Mccallum, C. 2001. Gender and sociality in Amazonia: how real people are made. Oxford/New York: Berg.

Nimuendajú, C. 1972. The Tukuna. UCPAAE, Vol. 45, Berkeley, Los Angeles.

Oliveira Filho, J. P. 1988. Nosso governo: os Ticuna e o regime tutelar. São Paulo: Marco Zero.

Otaviano, J. G. 2017. Relacionamentos homoafetivos: uma etnografia entre dois casais de mulheres Ticuna. Trabalho de Conclusão de Curso, Departamento de Antropologia Social, Universidade Federal do Amazonas, Benjamin Constant.

Overing, J. 1984. Dualisms as expression of difference and danger: marriage exchange and reciprocity among the Piaroa of Venezuela, in Marriage practices in lowland South American. Editado por K. M. Kinsinger, pp. 127-155. Urbana/Chicago: University of Illinois Press.

Pissolato, E. 2007. A duração da pessoa: mobilidade, parentesco e xamanismo mbya (guarani). São Paulo/ Rio de Janeiro: Editora da UNESP/NUTI.

Pissolato, E. 2012. Gênero, casamento e trocas com brancos, in Gênero e povos indígenas. Organizado por A. Sacchi e M. M. Gramkow, pp. 98-115. Brasília/Rio de Janeiro: Museu do Índio/FUNAI.

Porro, A. 1993. As crônicas do rio Amazonas: notas etno-históricas sobre as antigas populações indígenas da Amazônia. Petrópolis: Vozes. 
Ribeiro, V. J. 2019. O desafio da homossexualidade na comunidade indígena ticuna Vila de Betânea. Trabalho de Conclusão de Curso, Departamento de História, Universidade do Estado do Amazonas, Tefé.

Rosa, P. C. 2013. Romance de primas com primas e o problema dos afetos: parentesco e micropolítica de relacionamentos entre interlocutores tikuna, sudoeste amazônico. Cadernos Pagu (41):77-85. DOI: http://dx.doi.org/10.1590/S0104-83332013000200008.

Rosa, P. C. 2015. Das misturas de palavras e histórias: etnografia das micropolíticas de parentesco e os "muitos jeitos de ser Ticuna". Tese de Doutorado, Departamento de Antropologia Social, Universidade Estadual de Campinas, Campinas.

Rosa, P. C. 2016. Do “sexo malfeito”. Transformações morais e dispositivos de sexualidade indígena. Aceno 3(5):73-93.

Rubio, D. M. 2004. Formación del masá goro'personas verdaderas'. Pautas de crianza entre los macuna del bajo Apaporis. Tesis de Maestria en Estudios Amazónicos, Universidad Nacional de Colombia, Bogotá.

Santos Angarita, A. 2014. La constitución de naüne (cuerpo) entre los yunatügü (tikuna). Mundo Amazonico 5:327-356.

Schneider, D. 1980. American kinship: a cultural account. Englewood Cliffs: Prentice Hall.

Strathern, M. 2005. Kinship, law and the unexpected relatives are always a surprise. Cambridge: Cambridge University Press.

Strathern, M. 2006. O gênero da dádiva. Problemas com as mulheres e problemas com a sociedade na Melanésia. Campinas, SP: Editora da UNICAMP. 
Strathern, M. 2016. Before and after gender: sexual mythologies of everyday life. HAU Books. Cambridge: Cambridge University Press.

Taylor, A.-C. 1983. The marriage alliance and structural variations in Jivaro societies. Information (International Social Science Council) 22(3):331-353. DOI: https://doi.org/10.1177/053901883022003001. 